\title{
A MODEL QUESTIONNAIRE FOR EVALUATION OF MUSCULO SKELETAL DISORDER
}

\author{
Sanjit Kumar Kar
}

\begin{abstract}
Occupational health hazards are the very important unavoidable problems of different type of jobs. All occupational jobs contain several tasks and workers are compelled to adopt some harmful and awkward postures during performing those tasks. These types of repetitive jobs may be related to occupational health hazards like musculo skeletal disorder (MSD). In the present methodology different MSD related problems of the workers can be assessed by the questionnaire techniques considering the issues of community health development. In this concern a simple and easily applicable questionnaire technique has been established for the different occupations during performing tasks. It was concluded that MSD among the workers might be related to the stressful work posture, long duration jobs, nature of jobs and use of ill-fitted hand tools. So, with the application of the questionnaire, investigator can evaluate the real physiological problems and give them remedies.
\end{abstract}

\section{KEYWORDS:}

Occupation, Health hazards, MSD, Questionnaire.

1.Professor, Department of Physiology, Universal College of Medical Sciences, Ranigaon Campus, Bhairahawa, Nepal

\author{
For Correspondence: \\ Dr. Sanjit Kumar Kar \\ Professor \\ Department of Physiology \\ Universal College of Medical Sciences \\ Bhairahawa, Nepal \\ E-mail: drkarsk@gmail.com /drkarsk@rediffmail.com
}




\section{INTRODUCTION}

In different occupations human workforce contributes substantially for production. A large number of populations of different countries lives in villages. They maintain their livelihoods depending on different type of jobs like crop production, animal husbandry, tailoring, knitting, small scale industry or large scale industry etc. All the works of different jobs are repetitive in nature and may be related to musculoskeletal disorders (MSD). The workers either change their posture very frequently or they do not change their posture for long time. They may suffer from musculoskeletal disorder during performing their job in the same posture for long time. In a previous study, Goa and Coworkers ${ }^{1}$ were able to show that operators of VDT data entry work suffered from fatigue and increased stress. VDT workers, especially those who perform highly repetitive tasks, have reported pain and discomfort associated with the performance of their job ${ }^{2}$. In another study rapid upper limb assessment (RULA) was a survey method designed for use in ergonomic investigations of workplaces that report job-related upper limb disorders ${ }^{3}$. Smith et al. reported that the job content might be important factor for increased occupational stress and health complaints ${ }^{4}$. A large number of workers remained below the poverty line due to the number of family members higher than the normal status. Kar and Dhara in their study proved that the low socioeconomic status of the agricultural workers are related to their health and nutrition ${ }^{5,6}$. This may one of the reasons for the occurrence of occupational hazards. Berkson et $\mathrm{al}^{7}$ reported that physical effort, especially when it was sustained for long periods or was carried out in awkward stooping postures, appeared to result in significantly higher proportions of vertebral disc diseases, but not with the less definitive forms of back pain. Marras and Mirka ${ }^{8}$ have established that the risk of low back disorder (LBD) is increased as a function of lateral and twisting motions of trunk, trunk flexion angle and external moment. Hagberg, indicated that an experimental task of repetitive arm elevation caused shoulder tenderness in the region of the descending part of the trapezius muscles among patients with shoulder pain.

Similar findings were also noted from the study of Michelson and Helgemo ${ }^{1}$. Markolf et al. ${ }^{12}$ reported that the subjects might feel pain in the lower extremities due to imposition of static load on knee joints during continuous bent posture.

It appeared from the above results that the types of physical stress, work posture and methods of doing the job were associated with the musculoskeletal disorders. Vik et al. ${ }^{13}$ explained the relationship between physical work factors and MSD among forestry employees. Nag et al. ${ }^{14}$ in their study showed that about $68 \%$ of the women engaged in long term sewing work complained of back pain.

In the present methodology, efforts have been made to prepare a suitable questionnaire to assess the musculoskeletal disorder (MSD) of the workers engaged in different occupations considering issues of community health development as well as improvement of productivity.

\section{METHODS}

Investigators or researchers should make their protocol according to reliable workers of different occupations in their community or society, town or village, factory or industry, institution or market. The subjects should be select at random when they are working in different jobs considering male or female and age group separately.

\section{Evaluation of musculo skeletal disorder:}

We can evaluate musculo skeletal disorder (MSD) by questionnaire technique ${ }^{15}$, some of the disorders are assessed by direct observation method. A simple and easily applicable questionnaire is prepared for evaluating MSD of different occupational workers. Questions are asked to the subjects during work, just after finishing the work, and in the evening whenever they return to their home from the work stations. The full questionnaire is shown below:

\section{Questionnaire for Evaluating Musculo skeletal Disorders}

No:

Date :

Name of the subject:

Age and sex:

Length of service:

Name of the jobs:

(Please put ' $\sqrt{ }$ ' mark and write proper answer in appropriate blank space)

1. Do you feel any difficulties in your body during work? Yes/No

If yes, which part(s) of your body is/are affected most?......

2. Do you feel neck ache (Pain in neck) during work? Yes/No

3. Do you feel back ache (Pain in the back) during work? Yes/No

If yes, state the part experiencing pain...... Upper back/Lower back

4. Do you feel any problem in your hand during work? Yes/No

If yes, state the name of the parts being affected Fingers/Palm/Wrist joint/Lower arm/Elbow joint/ upper arm/Shoulderjoint $\backslash$ State the type of problem(s)

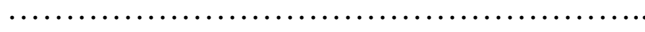
5. Do you feel any problem in your leg during work?
Yes/No

If yes, state the name of part(s) being affected................ Lower leg (Feet/ankle joint/knee joint)/Upper leg (Hip joint/Buttock)

6. Do you feel any problem in your eyes/ nose during work?

$\mathrm{Yes} / \mathrm{No}$

If yes, state the name and type/s of problem(s) $\quad \ldots \ldots \ldots . . .$. 
7. Do you feel head ache during work?

Yes/No

8. Do you feel any problem other than whichever stated above?

If yes, state the type of problem. Yes/No

9. How many times have you engaged in the job in a year? Whole year/.. Months/..Days

10. Are you engaged in other type of job except your occupation? Yes/No

If yes, State the type of job(s)

11. How many days have you done that job?

12. Are you Private or Government employee/worker? ... Private/Government

After collection of the information from the workers, researcher should analyze the problem and mention the results and discussion. According to their grade of problems, investigator can give them some suggestions and recommendations to reduce their occupational health hazards as far as possible.

\section{CONCLUSION}

The occurrence of MSD among the different occupational workers might be related to the work posture, duration of jobs, and use of ill-fitted hand tools. Low back pain may be the main problem during performing the different occupational tasks. It may be important cause of sickness and absenteeism. Occupational hazards may cause permanent changes in the discs, apophyseal joint, ligaments and other structures of the musculoskeletal system. Due to poor economic condition, the workers might have deprived of proper nutrition and could not avail suitable treatment for different health problems. Thus, musculoskeletal disorders became intensified. So, evaluation of occupational health hazards with special reference to musculoskeletal disorder has a great role to increase or decrease the productivity in occupational jobs. The sodesigned questionnaire will be effective in the evaluation of occupational hazards and the proper working technique, suitable precautions, occupational awareness and further treatment can be recommended according to the hazards.

\section{REFERENCES:}

1. Goa C, Lu D, She Q, Cail R, Yank L, Zhang G. The effect of VDT data entry on operators. Ergonomics 1990; 33: 917-24.

2. Occhipinti E, Colombini D, Frigo C, Pedotti A, Grieco A. Sitting posture analysis of lumber stress with upper limb supported. Ergonomics 1985; 28: 1333-46.

3. Mc Atamney L, Corlett EN. RULA: A survey method for the investigation of work-related upper limb disorders. Applied Ergonomics 1993; 17: 195-7.

4. Smith MJ, Cohen BCF, Stammerjohm LW, Happ A. An investigation of health complaints and job stress in video display operation. Human Factors 1981; 23: 387-99.
5. Kar SK and Dhara PC: An evaluation of musculoskeletal disorder and socioeconomic status of farmers in West Bengal, India. Nepal Medical College Journal, 2007, 9(4): 245-249.

6. Kar SK, Ghosh S, Paul R, De $S$ and Dhara PC: Ergonomic evaluation of occupational problems of women workers in agricultural tasks. International Journal of Basic and Applied Physiology, 2012, 1(1):103-108

7. Berkson M, Schultz A, Nachemson A, Anderson G. Voluntary strength of male adults with acute low back syndromes. Clin. Orthop 1977; 129:84-95.

8. Marras WS, Mirka GA. Trunk responses to asymmetric acceleration. J. Ortho. Rese 1990; 8: 824-32.

9. Hagberg M. Electromyographic signs of shoulder muscular fatigue in two elevated arm position. American Journal of Physical Medicine 1981a; 60: 111-21.

10. Hagberg M. Work load and fatigue in repetitive arm elevations. Ergonomics 1981b; 24: 543-53.

11. Michelson JD, Helgemo Jr. SL. Kinematics of the axially loaded ankle. Foot Ankle Int. 1995; 16: 577-87.

12. Markolf KL, Slauterbeck JL, Armstrong KL, Shapiro MM, Finnerman GA. Effects of combined knee loadings on posterior cruciate ligament force generation. J. Orthop. Res. 1996; 14: 633-44.

13. Nag PK, Chintharia S, Saiyed S, Nag A. EMG analysis at sitting work posture in work. Applied Ergonomics 1986; 17: 195-7.

14. Vik T, Hagen KB, Teige I. Occupational environment and health status of lumber jerks (in Norwegian). The Journal of the Norwegian medical Association 1984; 104: 2473-6.

Kuorinka, I., Jonson, B., Kilbom, A., Vinterberg, H., BieringSorenson, F., Anderson. $G$ and Jorgensen, K. Standardized Nordic questionnaire for the analysis of musculoskeletal symptoms. Applied Ergonomics 1987; 18: 233-237. 